\title{
Experimental Validation of Upward Electrospinning Process
}

\author{
Faissal Abdel-Hady, Abdulrahim Alzahrany, and Mostafa Hamed \\ Faculty of Engineering, King Abdulaziz University, Jeddah 21413, Saudi Arabia \\ Correspondence should be addressed to Faissal Abdel-Hady, faissalhady@gmail.com
}

Received 4 August 2011; Accepted 12 September 2011

Academic Editors: D. K. Sarker, D. Tsoukalas, and A. Turkovic

Copyright () 2011 Faissal Abdel-Hady et al. This is an open access article distributed under the Creative Commons Attribution License, which permits unrestricted use, distribution, and reproduction in any medium, provided the original work is properly cited.

\begin{abstract}
An experimental investigation has been carried out to validate the concept of a new upward electrospinning process in producing polymer nanofibres. The role of gravitational force in this concept is reversed from the conventional downward electrospinning. This inversion results in more stretching of the fibre, less bead formation, and jet stability. An experimental setup is built inside a vacuum chamber in order to eliminate the ambient effects. The effect of various parameters such as applied voltage, needle-collector distance, solution concentration, flow rate, and needle size, on average fibre diameter and beads formation, was investigated using scanning electron microscopy (SEM).
\end{abstract}

\section{Introduction to Conventional Electrospinning}

Electrospinning is a relatively simple process to produce nanofibre from polymer solutions or melts. Its roots go back to the early 1930s when the process was patented by Formhals [1-3]. The advantage of the electrospinning process is its technical simplicity and its easy adaptability. It is based mainly on applying an electrical field, by using high voltage source, between the tip of a nozzle and a collector in order to generate sufficient electrostatic force to overcome the surface tension in a droplet of polymer solution at the nozzle tip. When the surface tension is overcome, the hemispherical surface of the fluid at the tip of the nozzle stretches to form a conical shape known as the Taylor cone [4]. Further increase of the electric field's strength will deform the Taylor cone until a jet stream is extruded from the cone's apex. During the process, and depending on the solution properties and operating conditions, the solvent evaporates as the jet moves toward the collector which decreases the jet radius and increases the polymer concentration and viscosity. When the solvent is fully evaporated, the jet stretching stops and results in producing fibre of highly reduced diameter which deposits on the grounded collector in the form of a random nonwoven structure. The process of the electrospinning is well described in many papers [5-8]. Nanofibres in the range of 10 to $1000 \mathrm{~nm}$ diameter can be achieved by choosing the appropriate parameters such as viscosity, concentration, applied voltage, distance between the two electrodes, and nozzle tip (needle) diameters. However, the instability, the whipping of the fibre, and the beads formation remain important problems in the electrospinning process. This paper aims to validate experimentally the functionality of the new upward electrospinning approach introduced by Abdel Hady $[9,10]$. In this new approach, as the fibre formation is produced and a jet is directed upwards, the gravitational force and the surface tension will work against the electrostatic force, which introduces more stretching to the fibre.

\section{The New Upward Electrospinning Approach}

Electrospinning requires a very simple and economical setup; Figure 1 shows a schematic view of the conventional electrospinning (downward) setup. It consists of a nozzle, a collector, and of a high voltage electric source with positive or negative polarity. The nozzle may be a syringe needle or any other capillary tube; a syringe pump will carry the solution from the syringe to the nozzle. The collector can be made of any shape according to the requirements, like a flat plate or rotating drum, and separated from the nozzle by a defined distance. One electrode from the power supply is connected 


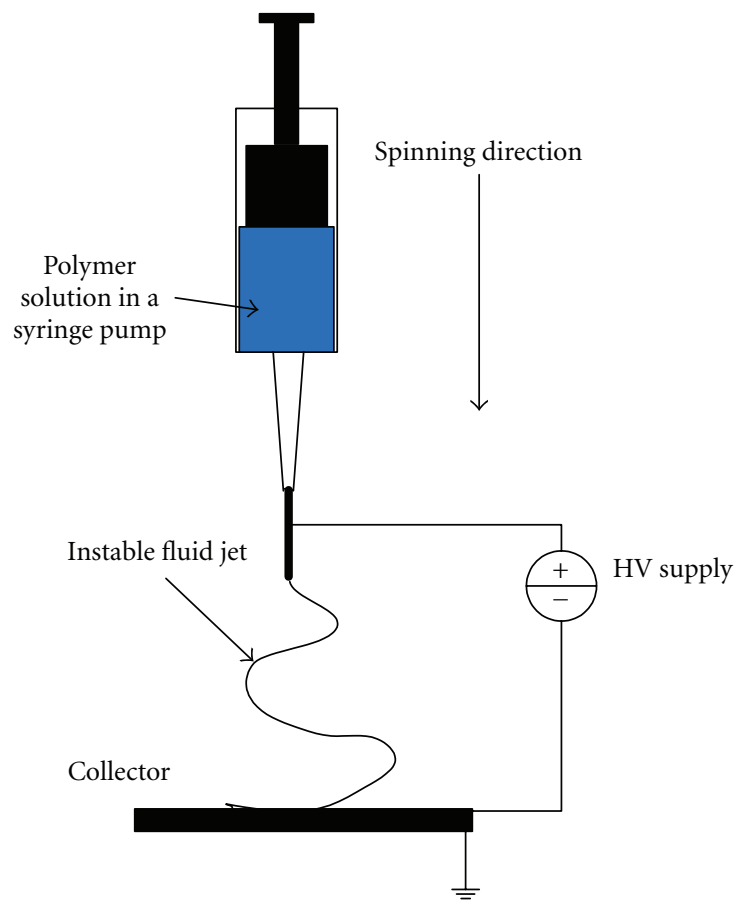

Figure 1: Conventional electrospinning setup.

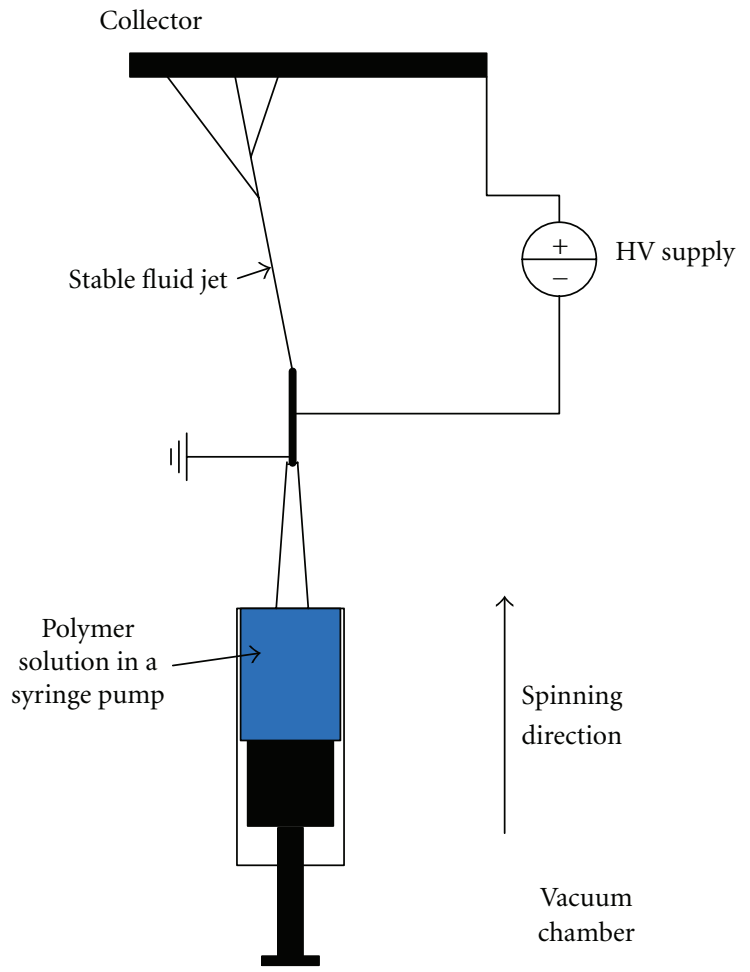

FIgURE 2: Upward electrospinning setup.

to the nozzle (needle) in order to charge the polymer solution and the other is attached to the opposite polarity collector (usually a grounded conductor).

Figure 2 shows a schematic view of the upward electrospinning setup. When the jet separates from the main fluid, acceleration will be gained upwards that will add more stretching, and even put the jet under stretching force until it reaches the collector electrode. The fibre collection at the collector electrode will take a uniform pattern instead of random orientation as produced with downward method 
and that is because the fibre is always under two balanced forces during its course of travel: the electrostatic and the gravitational forces. In addition, the fluid flow is mainly controlled by the amount of fluid withdrawn from the needle tip by the electrostatic force which insures that the formation of beads will be less than with the conventional downward process.

2.1. Instability. In conventional process, after the initiation from the cone, the jet undergoes a chaotic motion or bending instability and is field directed towards the opposite charged collector which collects the fibres [11]. Hohman et al. [12] in a series of papers studied the instability of an electrically forced fluid jet and its relation to the parameter space of electrospinning such as the applied electric field, the volume flux, and the liquid properties. They identified three different instabilities: the classical (axisymmetric) Rayleigh instability, another axisymmetric instability induced by the electric field, and the whipping (bending) instability. $\mathrm{He}$ [13] showed that the whipping instability in downward electrospinning process is due to slight air perturbation that leads to initiation of oscillation of small amplitude. This small oscillation increases as the fibre approach the collector forming what is known as whipping.

$\mathrm{He}$ [13] showed that the whipping instability in downward electrospinning process is due to slight air perturbation that leads to initiation of oscillation of small amplitude. This small oscillation increases as the fibre approach the collector forming what is known as whipping. Yu [14] examined the effect of fluid elasticity on Rayleigh instability. He found that, with dilute polymer solutions without elasticity, the electrospinning jet breaks up into droplets due to the Rayleigh instability driven by the surface tension. On the other hand, solutions with some degrees of elasticity can generate a stress that retards or halts the growth of the Rayleigh instability forming a "beads-on-string" structure; while in the extreme case, a large stress on the jet can suppress the Rayleigh instability completely, and uniform fibres are obtained. In the new proposed upward electrospinning approach, the Rayleigh and whipping instability will be eliminated due to two facts: (1) the process is performed under vacuum environment; (2) the gravitational and the electrostatic force acting on the jet during its travel to the collector are always in the opposite direction which leads to elimination of Rayleigh instability according to $\mathrm{Yu}$ [14].

\section{Experimental Setup and Materials}

3.1. Setup. An experimental setup was constructed to produce nanofibres by the new electrospinning process.

The process takes place in a sealed acrylic enclosure. This helps control the environment in which the electrospinning is taking place and that may affect the nanofibre production. The enclosure is kept under a vacuum condition of about4 psi using a double piston vacuum pump. The collector electrode is made of an electrically conducted material (aluminum or copper) and is mounted on an insulated stand inside the vacuumed enclosure. The polymer solution is fed from a syringe to a needle. The syringe that contains the polymer solution is mounted on a syringe pump located and centered with the collector electrode. The syringe pump allowed control of the flow rate and the volume of the polymer ejected which are two important parameters that affect the fibre production. Different diameters of syringe needles are used having the range of $19 \mathrm{G}$ down to $30 \mathrm{G}$. The distance between the collector and the injection needle tip can be adjusted by moving the collector electrode up and down. The high voltage supply module (Matsusada precision Inc. $60 \mathrm{KV}, 5 \mathrm{~mA}, 300 \mathrm{~W}$, and model AU-60*5) is connected to both the collector (positive) and syringe needle (ground or negative). The way we connect the needle and the collector is the opposite of the majority of published work where they use the positive terminal connected to the solution and the ground connected to the collector. It was found that the polarity does not affect the process of fibre formation.

3.2. Materials. Different polymer solutions of polycaprolactone (PCL), with a chemical formula $\left[\mathrm{O}\left(\mathrm{CH}_{2}\right)_{5} \mathrm{CO}\right]_{n}$, and a molecular weight of $80000 \mathrm{~g} / \mathrm{mol}$, were dissolved in acetone at different concentrations between 10 and $20 \%$. A magnetic stirrer is used to dissolve the polymer in acetone and the process of dissolving takes about 1.5 hours to complete under $20^{\circ} \mathrm{C}$. Raising the temperature to $35^{\circ} \mathrm{C}$ accelerate the process to 15 minutes.

\section{Procedure}

As in conventional electrospinning, the new approach process consists of three stages: process initiation (jet initiation), jet elongation, and jet solidification into nanofibres.

4.1. Process Initiation. In electrospinning, initiation of the process is important as maintaining of a stable jet. When a high voltage is applied to the needle, the surface of the fluid droplet held by its own surface tension and the gravitational force gets electrostatically charged. The droplet becomes under the action of two more forces: mutual electrostatic repulsion between the surface charges and the Coulombic force applied by the external electric field. This induces a charge on the surface of the droplet. This charge offsets the forces of surface tension and the droplet changes shape from spherical to conical where electric charges are concentrated on the tip of that conical shape. The accumulation of the electric charges causes the surface to extend more (Figures 3(a), 3(b), and 3(c)). The charge per unit area at the tip of the cone becomes higher as the radius of the cone, near the tip, decreases. At certain voltage, the intensity of the electric field attains a certain critical value; the electrostatic forces overcome the surface tension and the gravitational force of the polymer solution, and a jet of the liquid is pulled from the tip, and electrospinning process starts. The value of such voltage was found to be proportional to the distance between the needle tip and the collector regardless of the polymer solution concentration. Figure 4 shows the relation between the high voltage and the collector distance just enough to initiate the jet formation (blue dots). The concentration effect is not shown on the chart because 


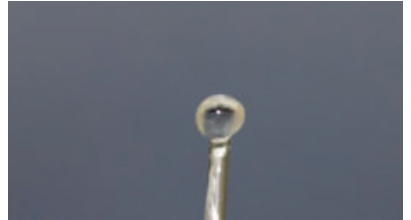

(a)

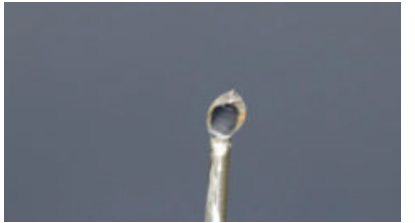

(b)

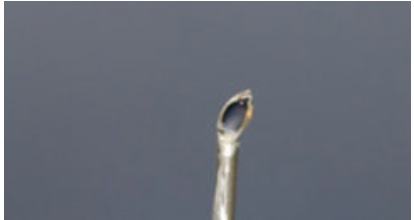

(c)

FIGURE 3: Jet initiation: (a) droplet created at the tip of the needle, (b) starting formation of Taylor cone, (c) ejection of the jet (pictures captured from a video clip of the process, three sequential frames).

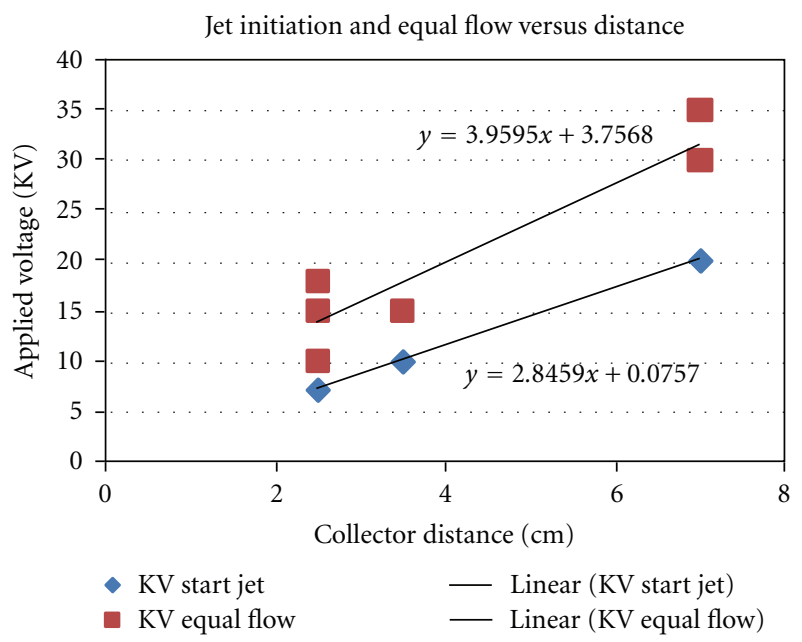

FIgURE 4: Relation between the applied HV and collector distance for jet initiation and equal flow condition.

different concentration values ( $10 \%$ to $20 \% \mathrm{w} / \mathrm{w})$ were found to have the same initiation voltage.

At the moment of jet ejection, the base of that jet takes the form of a cone that was described mathematically by Taylor [15]. The Taylor cone angle has been measured using solid works from an experiment photos (Figure 5). It was found to be $50.68^{\circ}$. In the literature, it was verified experimentally and found to be $50^{\circ}$; in another publication, it was reported that the Taylor cone's angle was $33.5^{\circ}$ instead of $49.3^{\circ}$ [16].

4.2. Jet Elongation. As the jet is formed, the electrostatic forces continue to accelerate the polymer solution and to stretch the jet against the surface tension (viscosity) force and gravity force. This makes the diameter of the jet thinner as it travels from the needle to the collector. It is observed that this stretching phenomenon is true as long as the solvent is not completely evaporated before the jet reaches the collector. So, we can conclude that with certain combination of high voltage value, needle-collector distance, and concentration of the diluted solution of the polymer, we can obtain much thinner fibre.

4.2.1. Droplet Enlarging. It was observed, in some cases that, with jet thinning, the droplet size is increasing with time forming a tube and multiple jets. This was likely to happen when the flow rate of the solution to the needle is larger than the rate of the ejected material. This case is shown in Figures 6 and 7. So, to maintain a continuous fibre formation, without dripping on the needle sides or formation of polymer tubes above the needle, the spinning parameters must be optimized such as the solution flow rate to the needle is equal to the rate of the ejected solution.

4.2.2. Splaying. Another phenomenon occurs during the electrospinning process; the jet can split or splay into multiple thinner jets, Figure 6. This happens in a region in which the radial forces from the electrical charges carried by the jet become larger than the cohesive forces within the jet, and the single jet divides into many charged jets with approximately equal diameters and charge per unit length [17]. Splaying and elongation occur simultaneously in many cases.

4.3. Jet Solidification. Evaporation and solidification is an important stage in the electrospinning process. It affects the diameter and morphology of the fibre. As the jet travels, the solvent gradually evaporates, the polymer jets solidify, and charged polymer nanofibres accumulate on the collector. The resulting product is a nonwoven fibre mat that is composed of tiny fibres with diameters between 40 nanometers and $1000 \mathrm{~nm}$. Factors such as solvent properties, the applied voltage, and the distance the jet travels have great effect on the evaporation of solvent. 


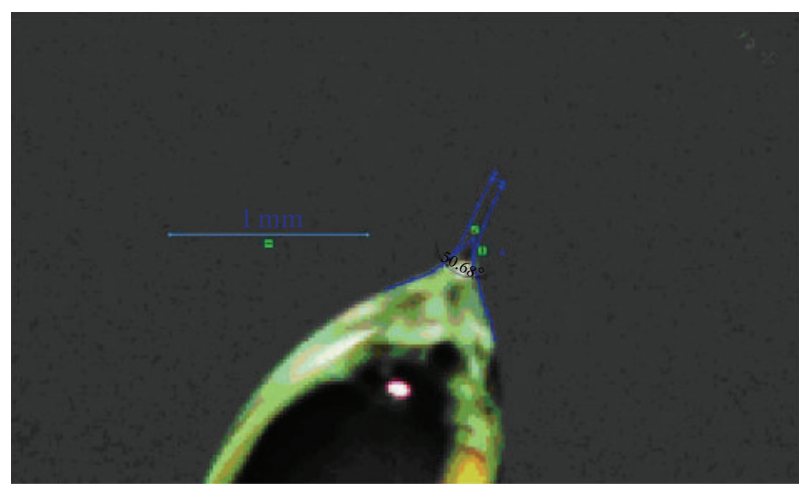

FIGURE 5: Taylor angle measured using solid works molder $\left(50.68^{\circ}\right)$, zoomed picture of Figure 3(c).

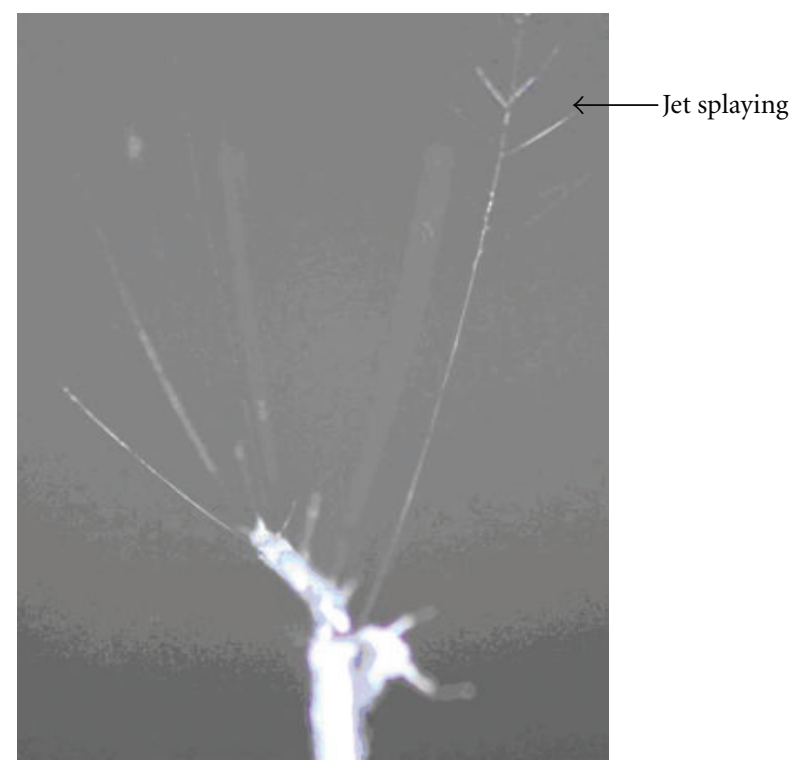

FIGURE 6: Formation of polymer tube and multiple jets in case of excess pumped solution.

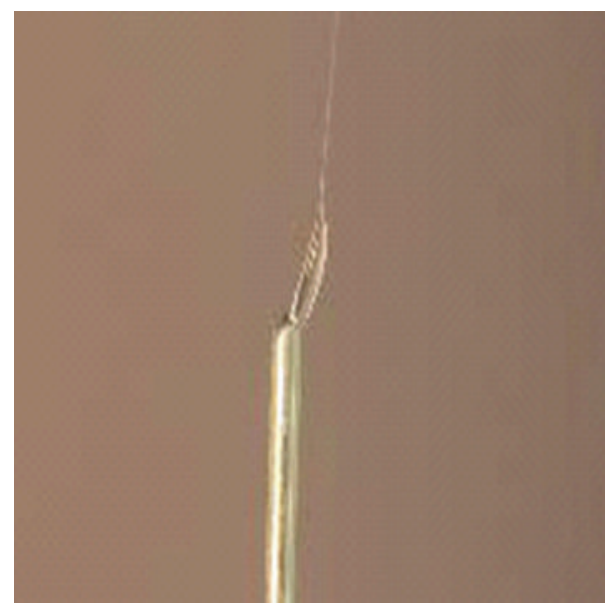

FIGURE 7: Droplet size increases with time as the flow into it exceeds the ejected materials. 


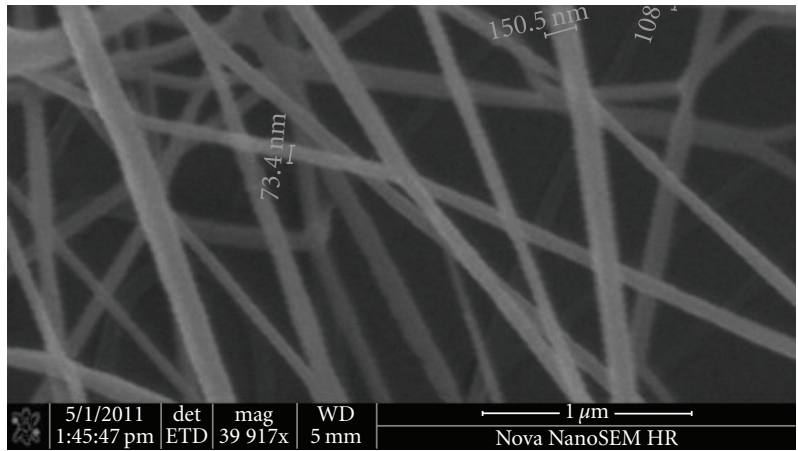

(a)

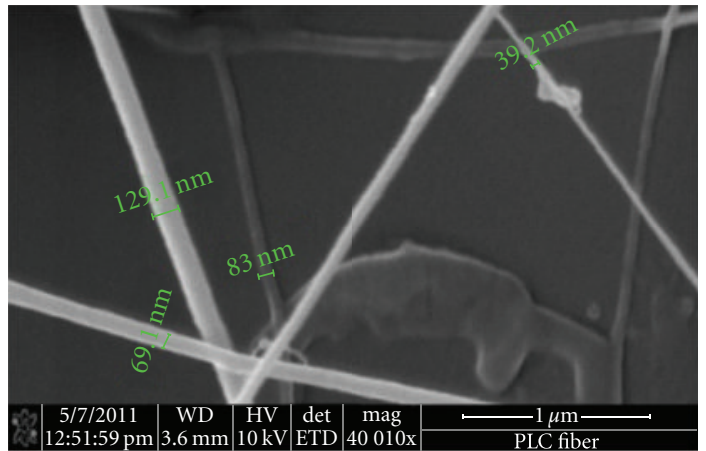

(b)

Figure 8: Effect of applied voltage on fibre diameter: (a) sample 1 with $15 \mathrm{KV}$ and average diameter of $100 \mathrm{~nm}$, (b) sample 12 with $30 \mathrm{KV}$ and average diameter of $78.5 \mathrm{~nm}$.

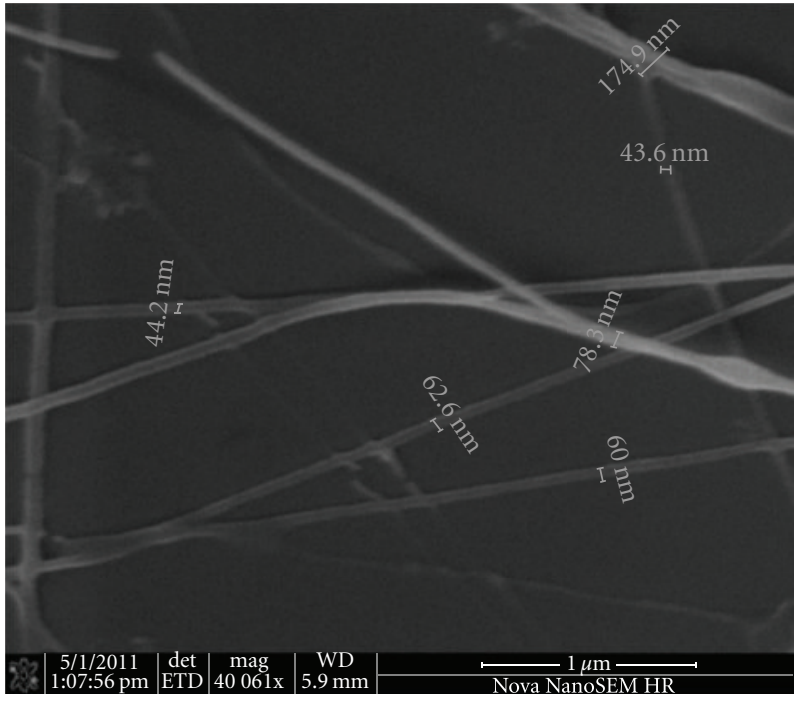

(a)

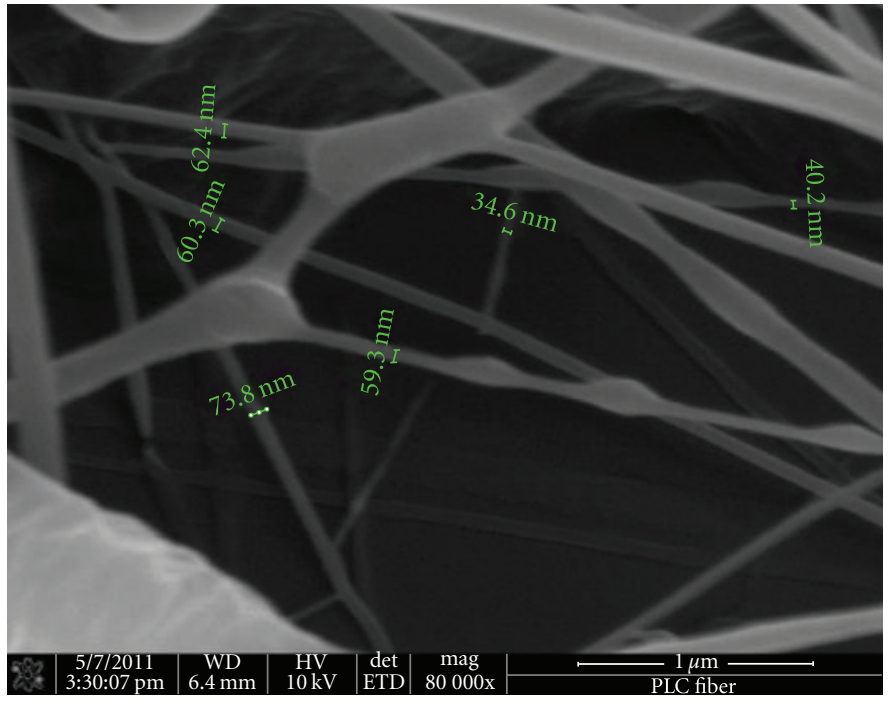

(b)

FIGURE 9: Effect of applied voltage; (a) sample 2 with $15 \mathrm{KV}$ and average diameter of $77.27 \mathrm{~nm}$, (b) sample 13 with $30 \mathrm{KV}$ and average diameter $55.10 \mathrm{~nm}$.

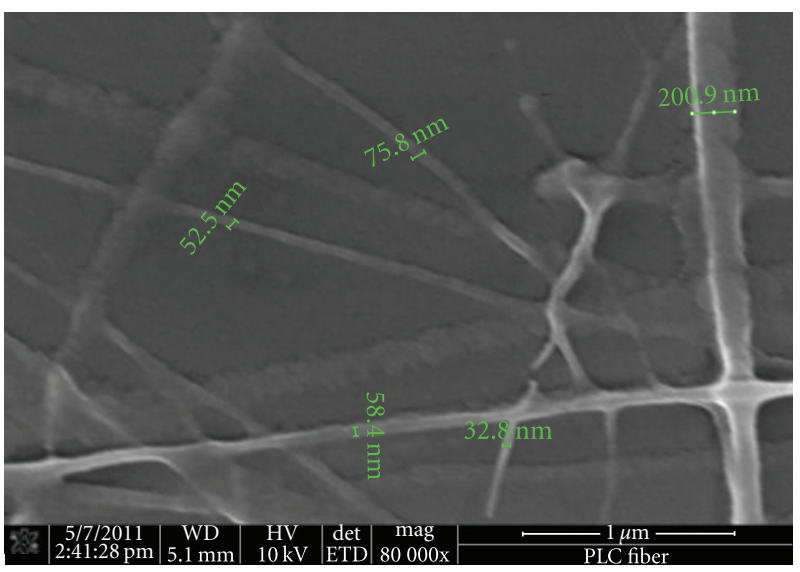

(a)

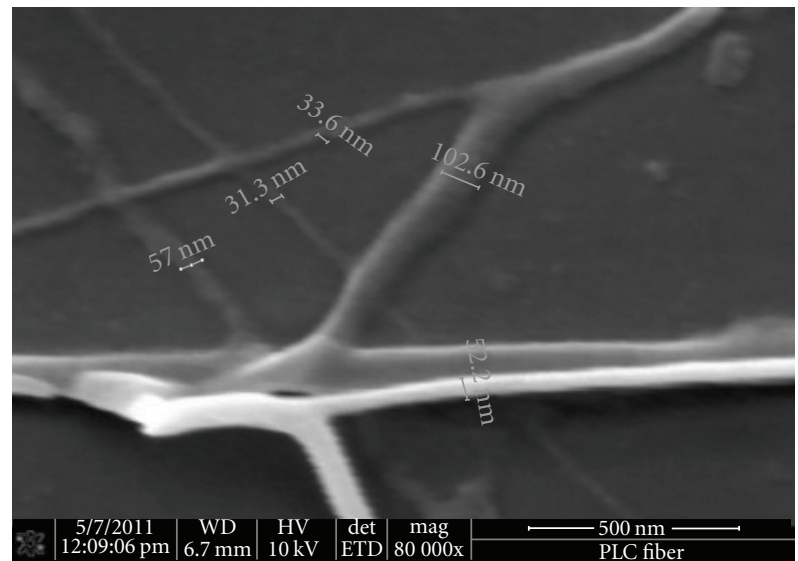

(b)

FigURE 10: Effect of increasing needle-collector distance on fibre diameter: (a) sample 6 at $7.5 \mathrm{~cm}$ and average diameter $82 \mathrm{~nm}$, (b) sample 7 at $15 \mathrm{~cm}$ and average diameter $55 \mathrm{~nm}$. 


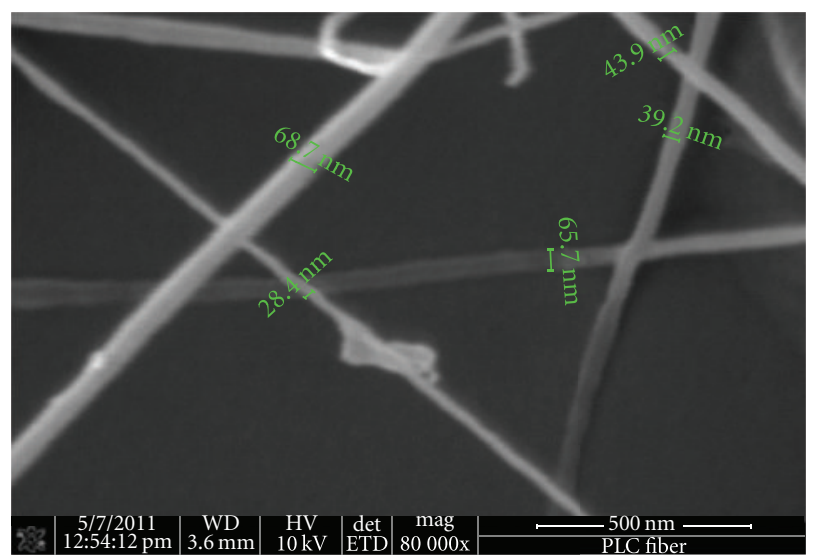

(a)

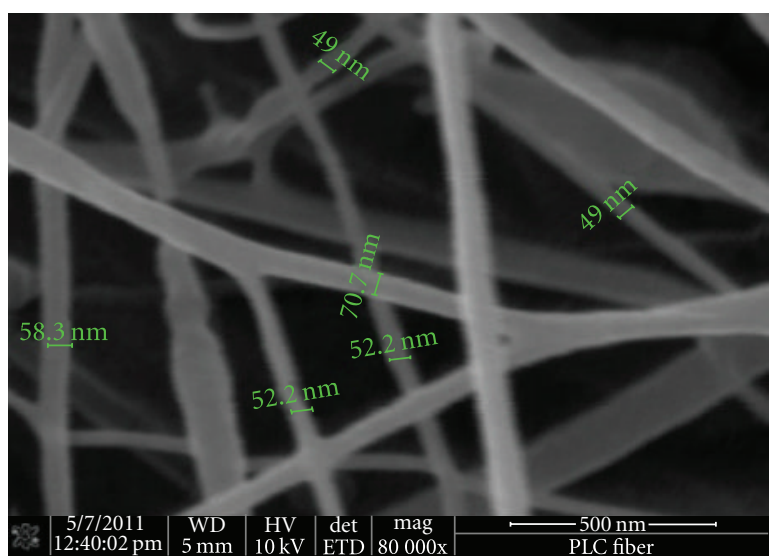

(b)

FIGURE 11: Effect of increasing needle-collector distance on fibre diameter: (a) sample 12 at $7.5 \mathrm{~cm}$ and average diameter $78 \mathrm{~nm}$, (b) sample 10 at $15 \mathrm{~cm}$ and average diameter $72 \mathrm{~nm}$.

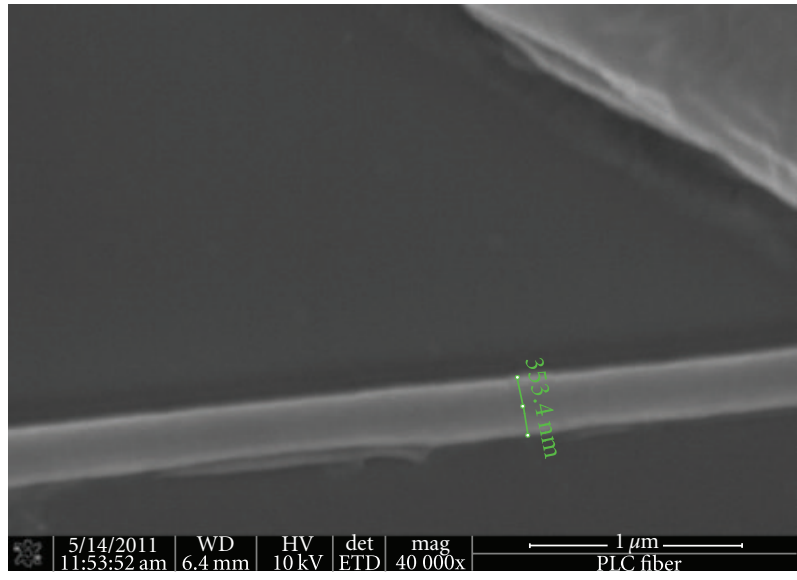

(a)

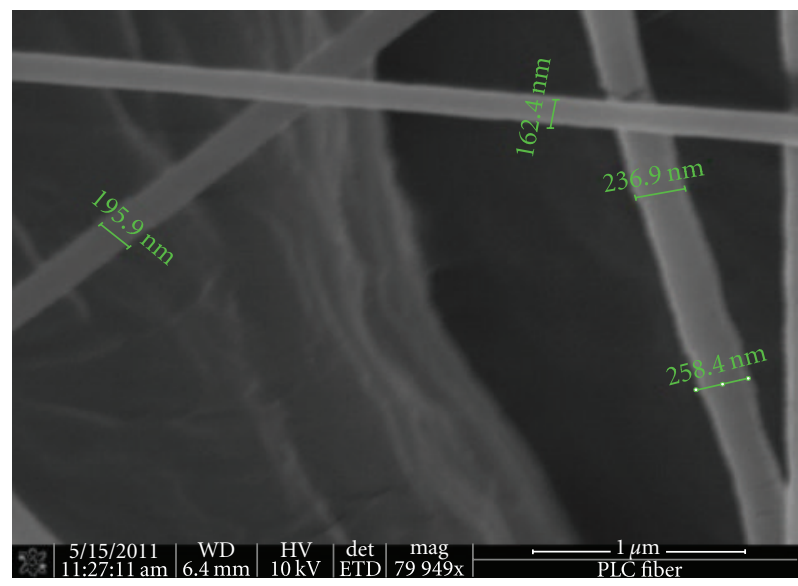

(b)

FigURE 12: Effect of increasing needle-collector distance on fibre diameter; (a) sample 21 at $7.5 \mathrm{~cm}$ and average diameter $353 \mathrm{~nm}$; (b) sample 20 at $15 \mathrm{~cm}$ and average diameter $196 \mathrm{~nm}$.

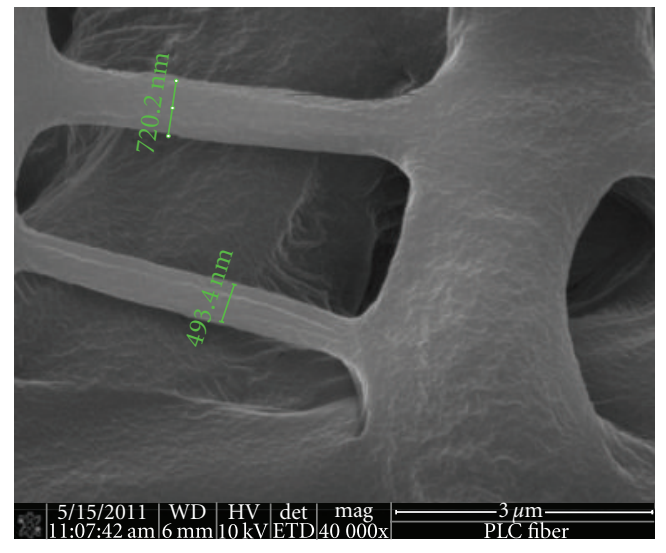

(a)

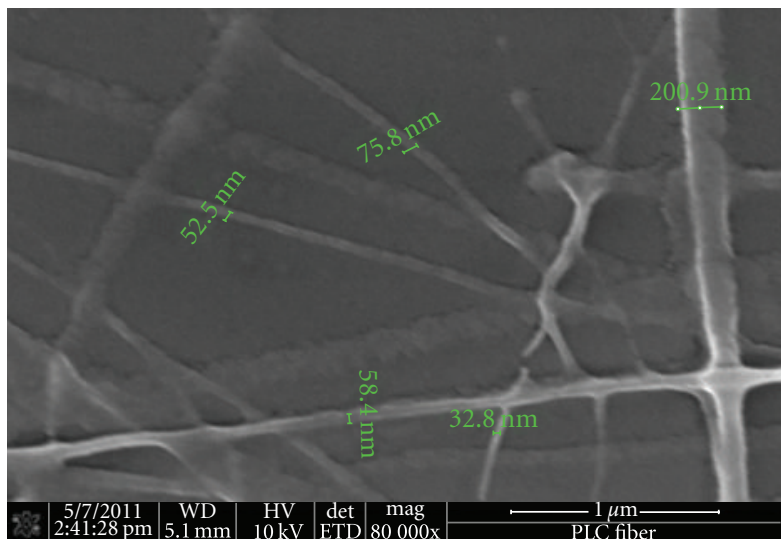

(b)

Figure 13: Effect of low needle-collector distance; a sample with $3.5 \mathrm{~cm}$ needle collector distance (a) compared to sample 7 with $15 \mathrm{~cm}$ distance (b). 


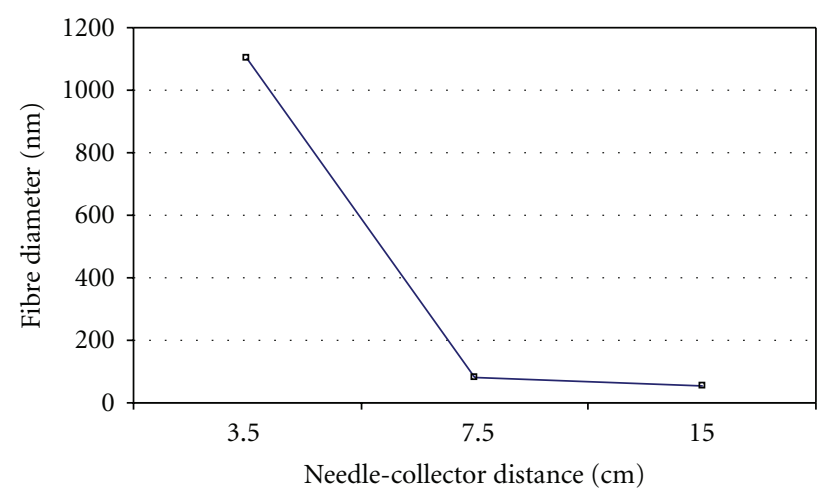

FIGURE 14: Effect of needle-collector distance on fibre diameter.

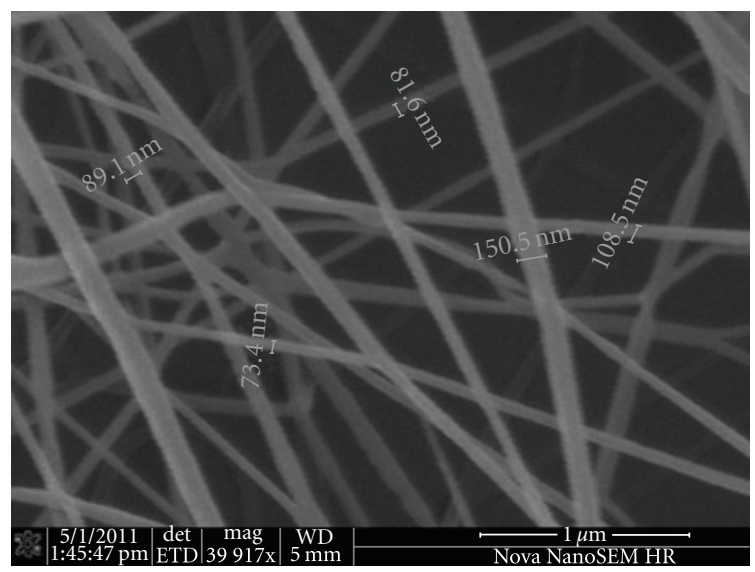

(a)

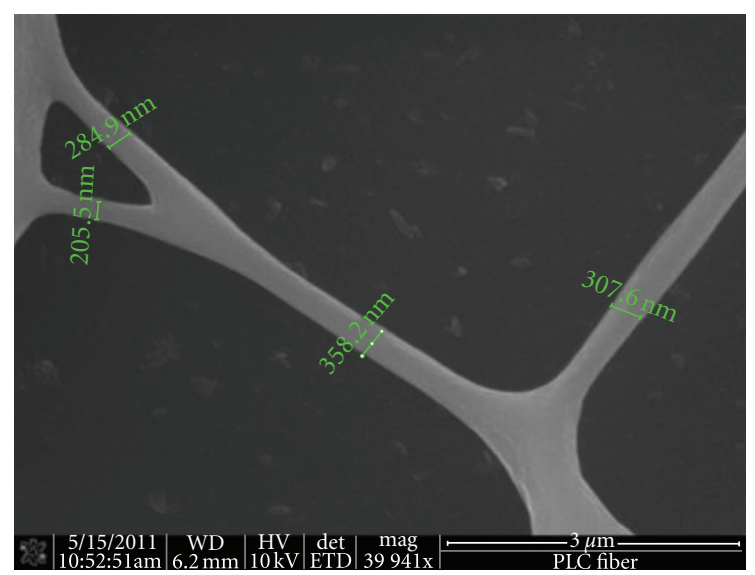

(b)

FIGURE 15: Effect of solution concentration on average fibre diameter: (a) sample 1 with concentration 10 wt\%, (b) sample 18 with concentration $20 \mathrm{wt} \%$.

\section{Results and Discussion}

5.1. Scan Electronic Microscopy (SEM) Characterization. In this study, we investigate the fibre diameters of the nanofibre produced by the new upward electrospinning technique and how they can be influenced by varying the process parameters. A SEM is used to characterize the fibres produced. We conducted electrospinning at different conditions. More than 30 samples are prepared on aluminum foil. The samples then coated with gold of a thickness of $5 \mathrm{~nm}$ to form a conductive layer. This conductive layer is essential for the SEM in order to prevent samples from charging and forming a source of reflecting electrons which may lead to a very poor quality of the image. Table 1 summarizes the parameters used in producing several samples.

5.2. The Effect of Voltage on the Average Diameter. The electrospinning process produces fibres only if the applied voltage is above certain value required to overcome the surface tension of the solution. The electrical field strength is proportional to the applied voltage, at constant needlecollector distance. Higher electric field values are obtained either through decreasing the distance between the tip and collector or by applying higher voltages. There exists controversy in the literature as to the effect of increasing the voltage on the final diameter of the electrospun nanofibre. Some researches assert that stretching of the jet, which leads to smaller fibre diameters, increases with the applied voltage $[18,19]$. In the present work it was found that the fibre diameter decreases with the increase of the applied voltage. In Figure 8, sample 1 shows an average diameter of $100.62 \mathrm{~nm}$ at $15 \mathrm{kv}$, while sample 12 has an average diameter of $78.50 \mathrm{~nm}$ at $30 \mathrm{kv}$. The same effect can be seen in Figure 9 between sample 2 of $77.27 \mathrm{~nm}$ diameter at $15 \mathrm{kv}$ and sample 13 of $55.10 \mathrm{~nm}$ diameter at $30 \mathrm{kv}$.

On other hand, some researchers reported that there is no significant effect of the applied voltage on average fibre diameter $[20,21]$. And others even reported that there is a diameter increase with the increase in the applied voltage [22-24]. Based on the conventional electrospinning setup where the solution is ejected downwards, this discrepancy can be explained. As the voltage increases, the solution flow rate will increase due to higher electrostatic force acting on the charged jet. This phenomena increases as the gravity force is working with the electrostatic force. Moreover, in some situation, these forces are able to separate a whole droplet before forming a jet initiation cone. In the new proposed upward setup where the gravitational force is 


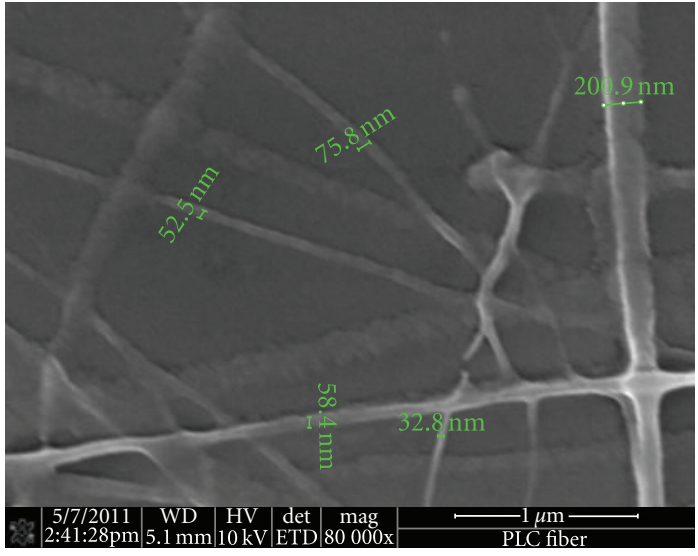

(a)

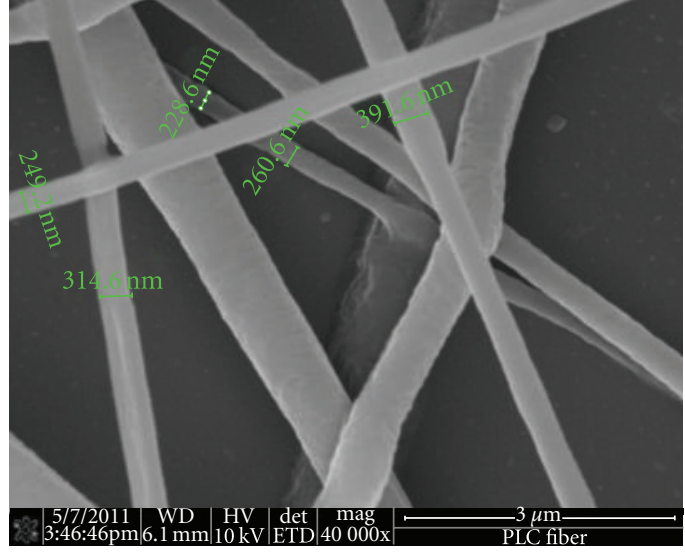

(b)

FIGURE 16: Effect of solution concentration on average fibre diameter: (a) sample 6 with concentration $10 \mathrm{wt} \%$, (b) sample 17 with concentration $20 \mathrm{wt} \%$.

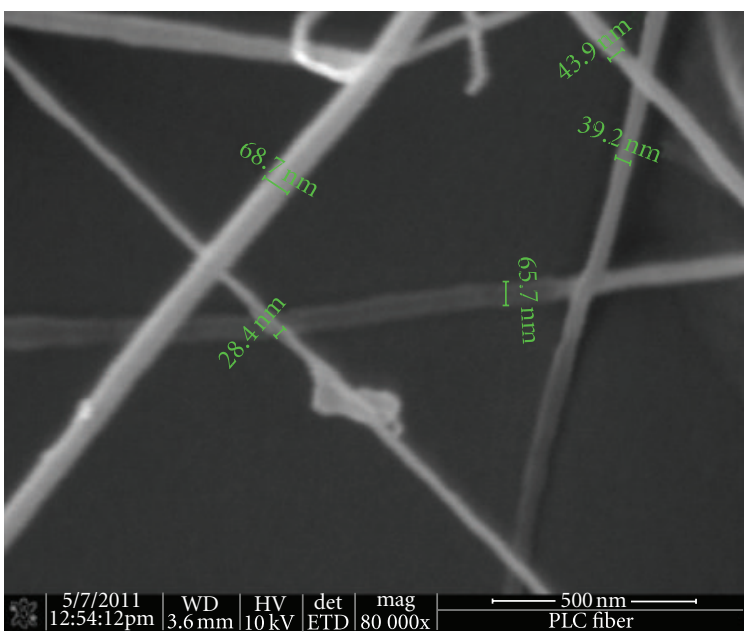

(a)

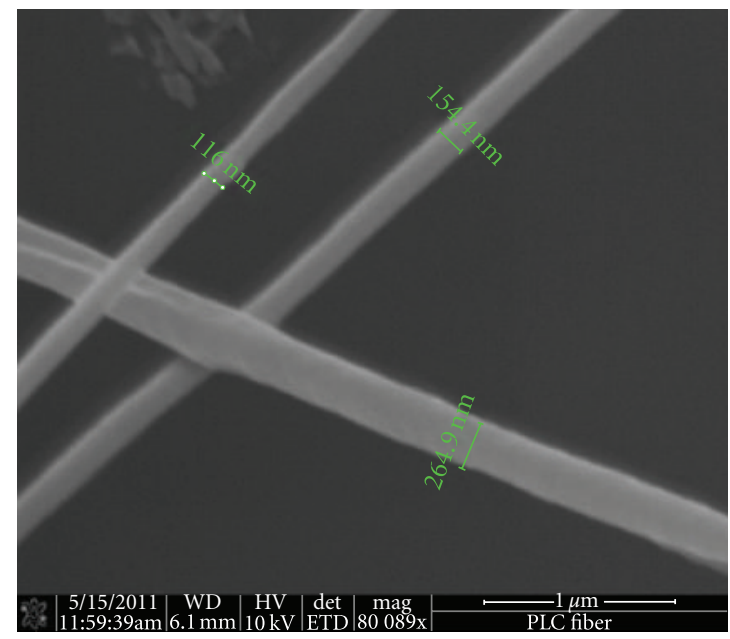

(b)

Figure 17: Effect of solution concentration on average fibre diameter: (a) sample 12 with concentration 10 wt $\%$, (b) sample 23 with concentration $20 \mathrm{wt} \%$.

working against the electrostatic force, even if a droplet is separated from the nozzle, the electrostatic force will not be enough to pull up to the collector. This is exactly what happens during our experiments. When a droplet separates, it falls aside and never reaches the collector. But this does not mean that there is no bead formation in some situations.

\subsection{Effect of Needle-Collector Distance on the Average Fibre} Diameter. The needle-collector distance defines the strength of the electric field as well as the time available for evaporation of the solvent before the nanofibres reach the collector surface. It was found that with increasing the needlecollector distance, keeping the other parameters constant, the fibre diameter decreases. This trend is true regardless of the concentration of the polymer in the solution. Figures 10, 11, and 12 show the effect of needle-collector distance on fibre diameter where the mean average diameter is reduced with the increase of the distance. Figure 13 represents a sample of the same parameters as sample $7(15 \mathrm{~cm}$ distance $)$ but with a needle-collector distance of $3.5 \mathrm{~cm}$. It is seen that at such small needle-collector distance the solvent has no enough time to evaporate or even to stretch, as well as an increase in the electric field results in increase of bead formation and wet fibres hitting the surface of the collector. Figure 14 illustrates the difference between the distances of $3.5 \mathrm{~cm}$ and $15 \mathrm{~cm} 0.5$. These results are consistent with many others in the literature such as $[17,18,23,25]$.

5.4. The Effect of Solution Concentration on the Average Fibre Diameter. The concentration of polymer in solution generally has a dominant effect on the fibre diameter as well as fibre morphology. Solution concentration has been found to most strongly affect fibre size, with fibre diameter increasing with increasing solution concentration $[26,27]$. 


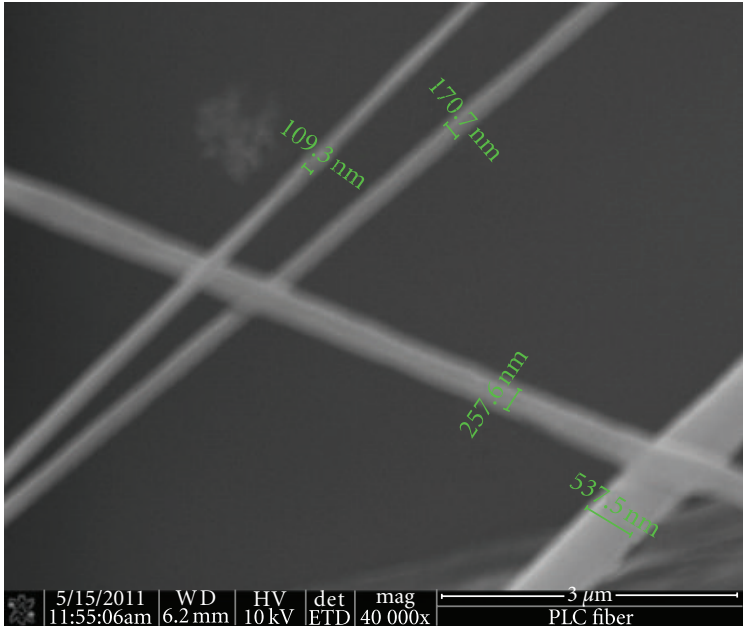

(a)

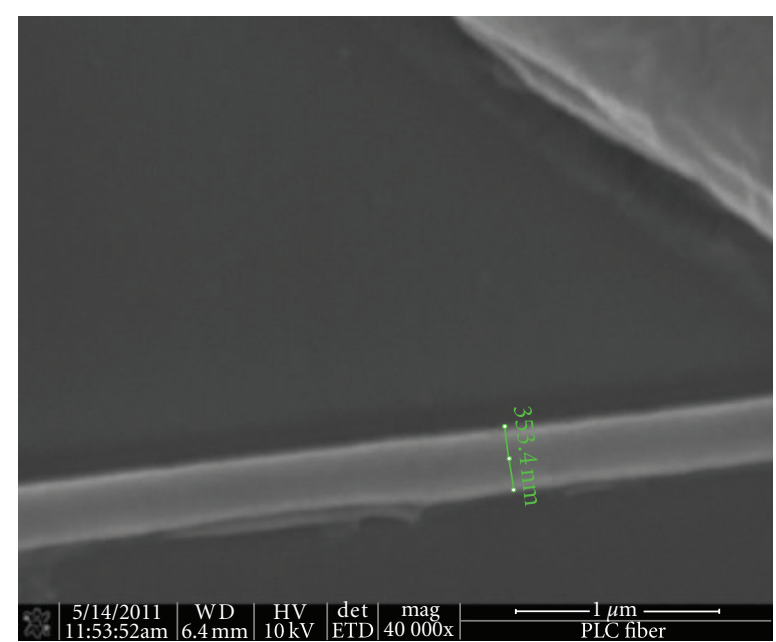

(b)

FIGURE 18: Effect of flow rate on fibre diameter: (a) sample (23) with flow rate $25 \mu \mathrm{L} / \mathrm{min}$, (b) sample 21 with flow rate $50 \mu \mathrm{L} / \mathrm{min}$.

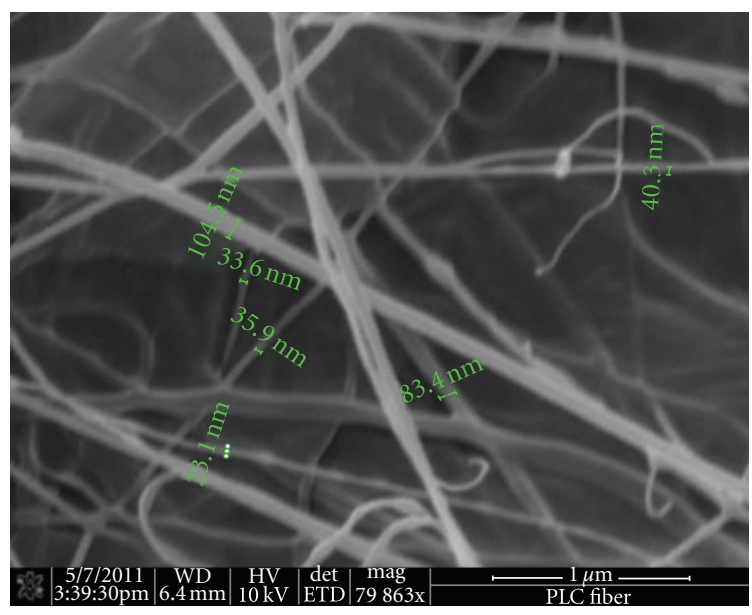

(a)

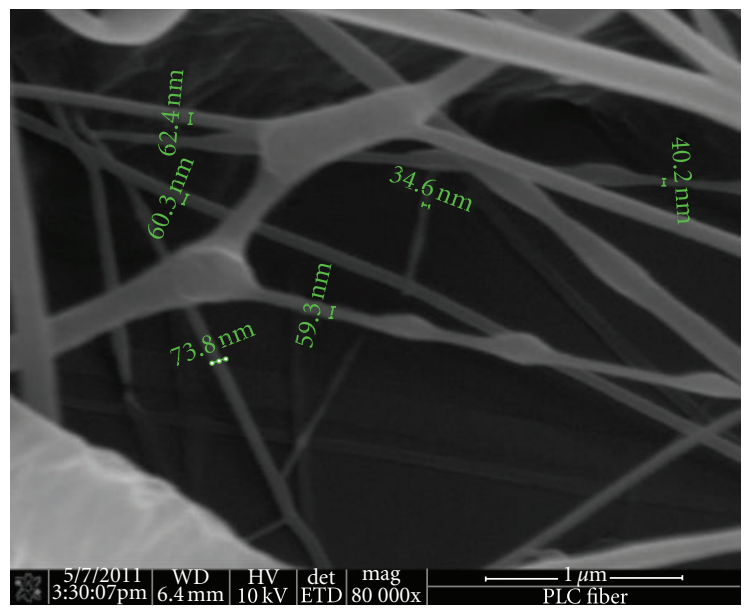

(b)

Figure 19: Effect of flow rate on fibre diameter: (a) sample (14) with flow rate $25 \mu \mathrm{L} / \mathrm{min}$, (b) sample 13 with flow rate $50 \mu \mathrm{L} / \mathrm{min}$.

This was also found in the present study. Higher concentrations generally yield nanofibres of larger average diameter. Figures 15, 16, and 17 show the effect of two different concentrations $10 \mathrm{wt} \%$ to $20 \mathrm{wt} \%$ on three two-set samples ( 1 and 18, 6 and 17, 12 and 23). It is deduced that the increase of the concentration leads to the increase in the diameter by about 3 times: first set from $100 \mathrm{~nm}$ to $289 \mathrm{~nm}$, second set from $82 \mathrm{~nm}$ to $288 \mathrm{~nm}$, and third set from $78 \mathrm{~nm}$ to $268 \mathrm{~nm}$. Solutions with high polymer content may not only impede the fibre-extension process, yielding relatively thicker nanofibres, but may also make it difficult to pump the polymer solution because of its high viscosity.

5.5. The Effect of Flow Rate on the Average Diameter. At lower feed rates, electrospinning may be intermittent with the Taylor's cone being depleted; the cone even retreating into the needle in some cases. On the other hand, at higher feed rates, larger fibre diameters and beads often result. Increasing the feed rate under conditions where applied potential is not a limiting factor results in the increasing in the average fibre diameter. The comparison of sample 21 $(50 \mu \mathrm{L} / \mathrm{min})$ and sample $23(25 \mu \mathrm{L} / \mathrm{min})$ shows a decrement of fibre diameter from $353.40 \mathrm{~nm}$ to $268.77 \mathrm{~nm}$. In the second comparison, the diameter of sample $13(50 \mu \mathrm{L} / \mathrm{min})$ was $55.10 \mathrm{~nm}$ and for sample $14(25 \mu \mathrm{L} / \mathrm{min})$ was $53.47 \mathrm{~nm}$. The last one was between sample $10(25 \mu \mathrm{L} / \mathrm{min})$ and sample $11(50 \mu \mathrm{L} / \mathrm{min})$, and it shows increasing from $72.77 \mathrm{~nm}$ to $78.50 \mathrm{~nm}$ (Figures 18, 19, and 20).

5.6. The Effect of Needle Diameter on the Average Diameter. In general, smaller diameter capillaries yield fibres of smaller diameter. Yet, pumping a viscous liquid through a needle of small internal diameter may not always be practical. Figures 21,22 , and 23 show the effect of two different needle sizes 


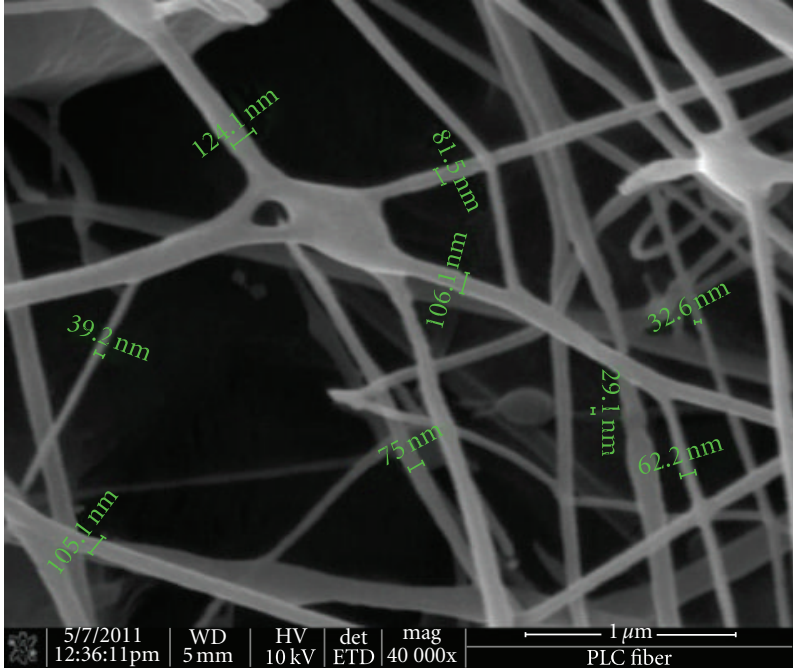

(a)

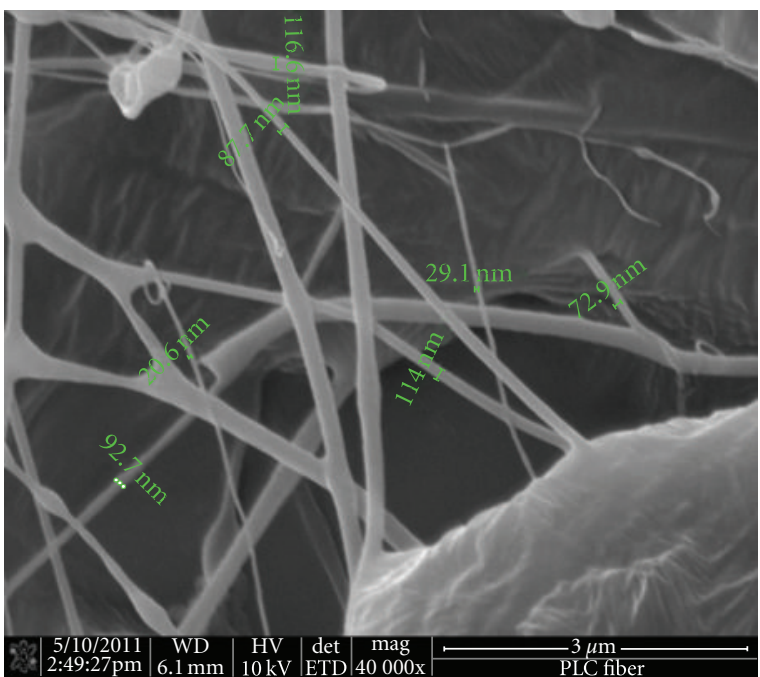

(b)

Figure 20: Effect of flow rate on fibre diameter: (a) sample (10) with flow rate $25 \mu \mathrm{L} / \mathrm{min}$, (b) sample 11 with flow rate $50 \mu \mathrm{L} / \mathrm{min}$.

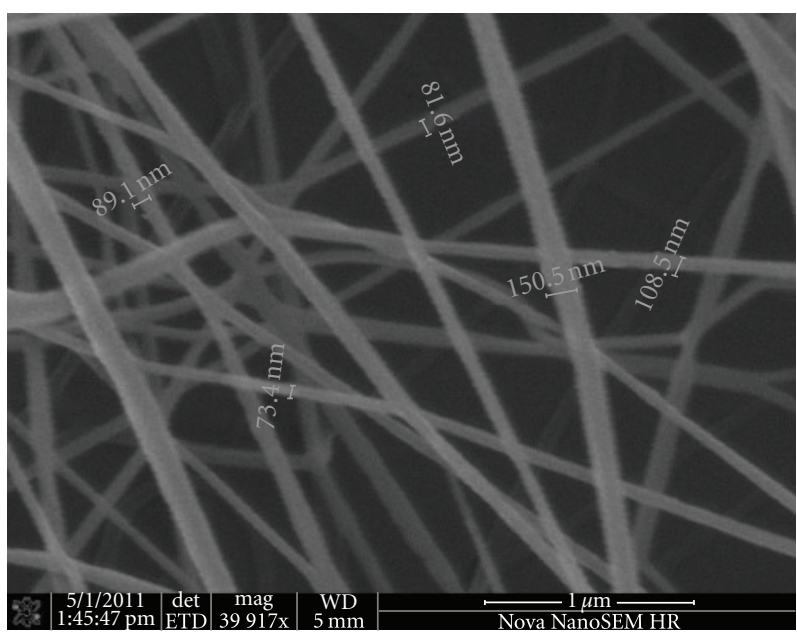

(a)

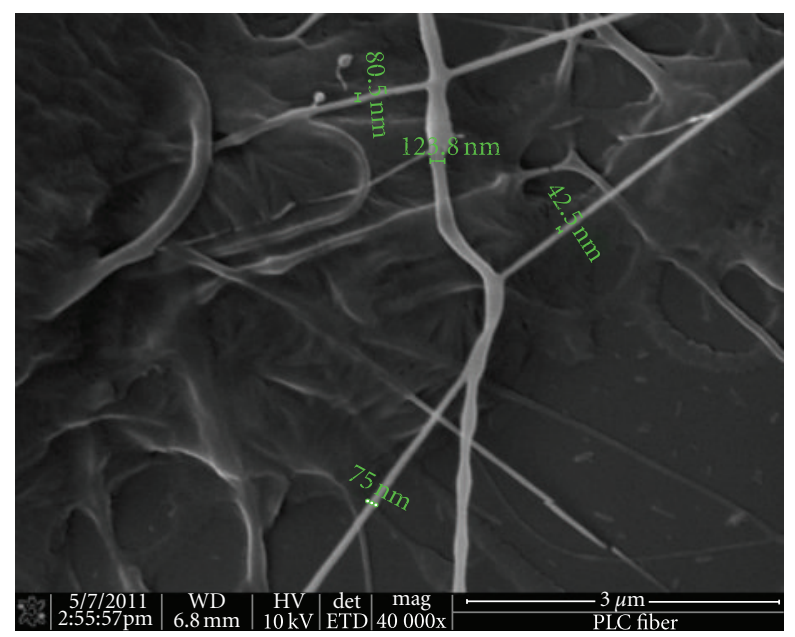

(b)

Figure 21: Effect of needle size on average fibre diameter: (a) sample 1 with needle size 22 G, (b) sample 3 with needle size 27 G.

$22 \mathrm{G}$ and $27 \mathrm{G}$ on three two-set samples (1 and 3, 18 and 16, 11 and 13); it is deduced that the diameter always decreases when the needle diameter decreases: first set from $100.62 \mathrm{~nm}$ to $80.45 \mathrm{~nm}$, second set from $289.05 \mathrm{~nm}$ to $234.78 \mathrm{~nm}$, and third set from $76.22 \mathrm{~nm}$ to $55.10 \mathrm{~nm}$.

5.7. Statistical Results. Based on the data of 25 samples (Table 1), the frequency of occurrence of the average diameter is given in Figure 24. The majority of fibre diameters drop between $43.23 \mathrm{~nm}$ and $196 \mathrm{~nm}$. The mean value of the diameter was found to be $164 \mathrm{~nm}$.

Figure 25 shows the effect of the different process parameters on the average fibre diameter. It was found that the concentration has the greatest effect on the diameter. The interaction of the concentration and the needle-collector distance has the second major effect on the fibre diameter.
The lowest effect on the fibre diameter was found to be the interaction of the needle-collector distance and the needle diameter.

\section{Conclusion}

The upward electrospinning process proved to be a valid process in producing nanofibres in the range of $50 \mathrm{~nm}$ to $1000 \mathrm{~nm}$. As well, the new process has the advantage to eliminate the whipping instabilities; in turn a well-defined nanostructure can be produced. Yet some adjustment in the setup needs to be taken in consideration furthermore, a number of fundamental aspects of the process for different polymer-solvent systems are still worthy of further investigation in order to gain a thorough understanding of the upward process. The effect of different spinning parameters 


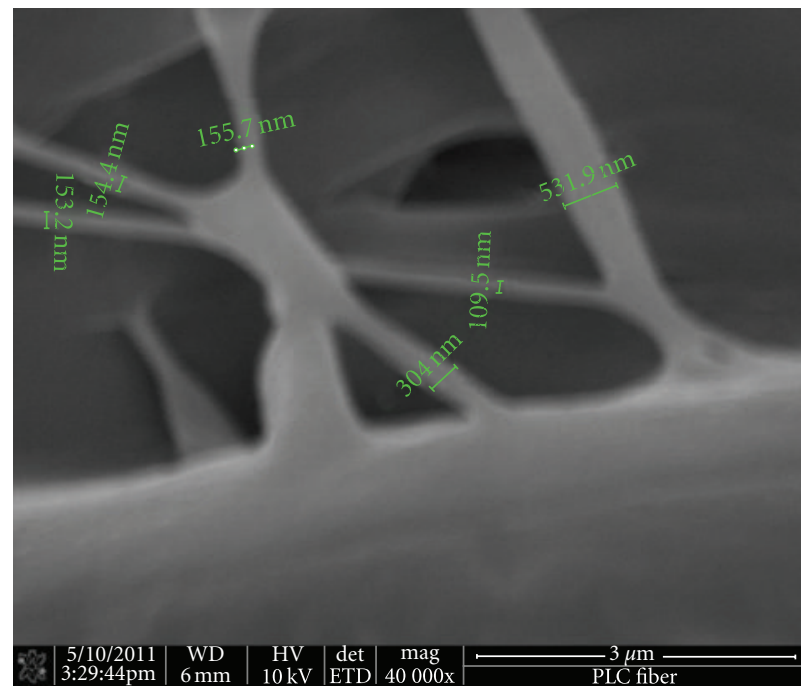

(a)

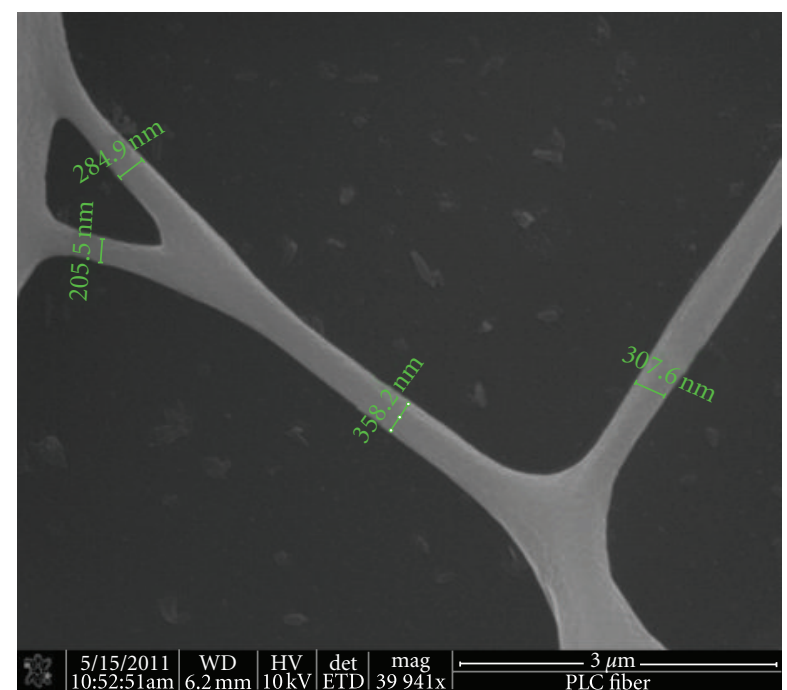

(b)

FigURE 22: Effect of needle size on average fibre diameter: (a) sample 18 with needle size 22 G, (b) sample 16 with needle size 27 G.

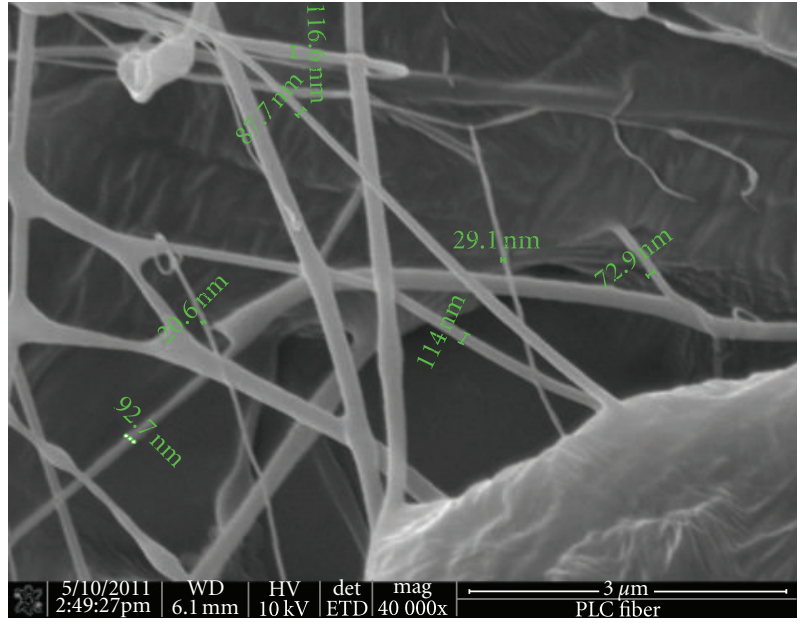

(a)

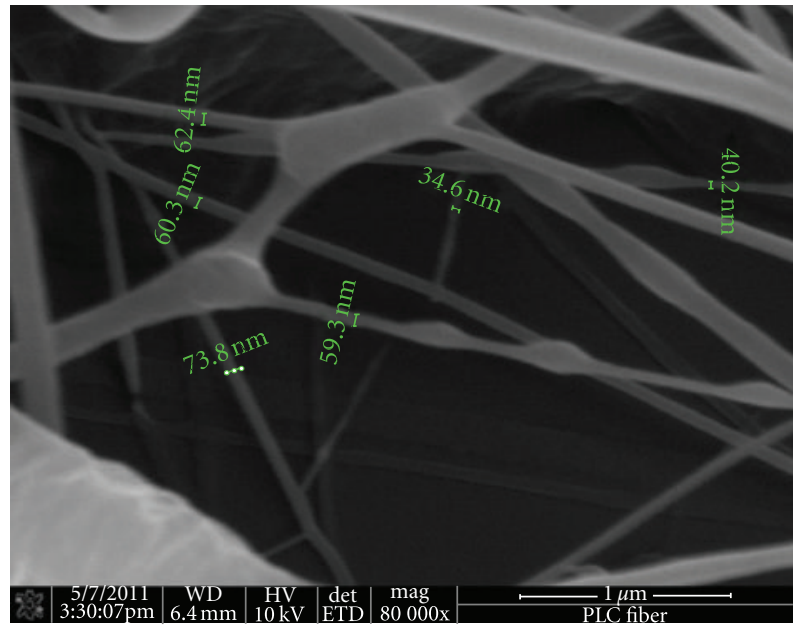

(b)

Figure 23: Effect of needle size on average fibre diameter: (a) sample 11 with needle size 22 G, (b) sample 13 with needle size 27 G.

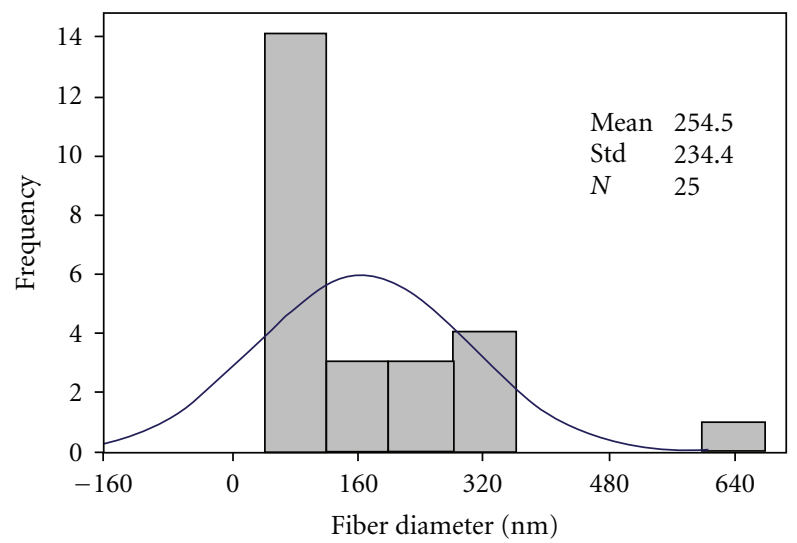

Figure 24: Histogram of the average fibre diameter. 


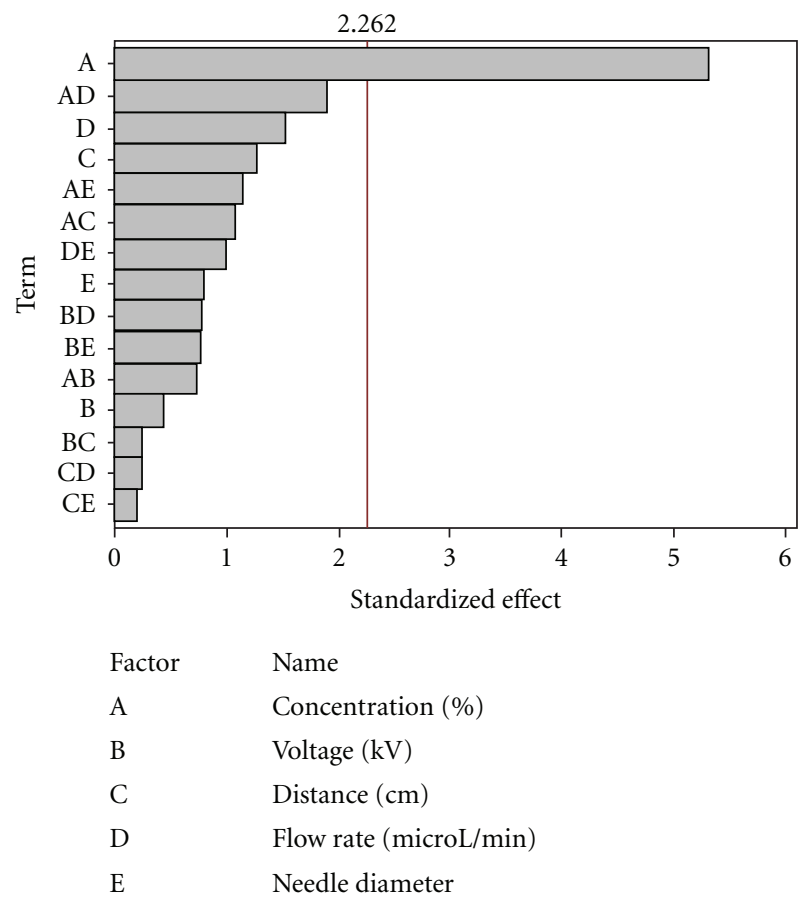

Figure 25: Pareto chart of the standardized effects.(response is fiber diameter $(\mathrm{nm})$, Alpha $=0.05)$

TABLE 1: List of samples and different parameters used.

\begin{tabular}{|c|c|c|c|c|c|c|}
\hline Sample no. & Conc. \% & Voltage (KV) & Distance $(\mathrm{cm})$ & Flow rate $(\mu \mathrm{L} / \mathrm{min})$ & Needle gauge $(\mathrm{G})$ & Fibre diameter $(\mathrm{nm})$ \\
\hline 1 & 10 & 15 & 7.5 & 25 & 22 & 100.62 \\
\hline 2 & 10 & 15 & 15 & 50 & 27 & 77.27 \\
\hline 3 & 10 & 15 & 7.5 & 25 & 27 & 80.45 \\
\hline 4 & 10 & 15 & 7.5 & 50 & 27 & 43.23 \\
\hline 5 & 10 & 15 & 15 & 25 & 22 & - \\
\hline 6 & 10 & 15 & 7.5 & 50 & 22 & 82.27 \\
\hline 7 & 10 & 15 & 15 & 50 & 22 & 55.43 \\
\hline 8 & 10 & 30 & 7.5 & 50 & 27 & 75.33 \\
\hline 9 & 10 & 30 & 7.5 & 50 & 22 & 58.50 \\
\hline 10 & 10 & 30 & 15 & 25 & 22 & 72.77 \\
\hline 11 & 10 & 30 & 15 & 50 & 22 & 76.22 \\
\hline 12 & 10 & 30 & 7.5 & 25 & 22 & 78.50 \\
\hline 13 & 10 & 30 & 15 & 50 & 27 & 55.10 \\
\hline 14 & 10 & 30 & 15 & 25 & 27 & 53.47 \\
\hline 15 & 10 & 30 & 7.5 & 25 & 27 & 75.40 \\
\hline 16 & 20 & 15 & 7.5 & 25 & 27 & 234.78 \\
\hline 17 & 20 & 15 & 7.5 & 50 & 22 & 288.92 \\
\hline 18 & 20 & 15 & 7.5 & 25 & 22 & 289.05 \\
\hline 19 & 20 & 15 & 7.5 & 50 & 27 & 606.80 \\
\hline 20 & 20 & 30 & 15 & 50 & 22 & 196 \\
\hline 21 & 20 & 30 & 7.5 & 50 & 22 & 353.4 \\
\hline 22 & 20 & 30 & 15 & 25 & 22 & 156.25 \\
\hline 23 & 20 & 30 & 7.5 & 25 & 22 & 268 \\
\hline 24 & 20 & 30 & 15 & 25 & 27 & 171.83 \\
\hline 25 & 20 & 30 & 7.5 & 50 & 27 & 294.94 \\
\hline
\end{tabular}


on the average fibre diameter was studied and the following was found. Concentration has the greatest effect on nanofibre diameter. Increasing the concentration leads to increasing in fibre diameter. The interaction of the concentration and the needle-collector distance has the second major effect on the fibre diameter. The lowest effect on the fibre diameter was found to be the interaction of the needle-collector distance and the needle diameter. Increasing the needle-collector distance leads to decreasing in nanofibres diameter. The change in applied high voltage on nanofibres diameter has a linear relationship; as the applied high voltage increases, nanofibres diameter decreases. Increasing the feed rate leads to increasing in fibre diameter and increasing in bead formation. Smaller needle diameter yields fibres of smaller diameter; yet pumping a viscous liquid through a needle of small internal diameter may not always be practical. Fibres of the size produced may potentially be used into many applications such as microfiltration and in a drug release control of some insoluble drugs.

\section{Acknowledgments}

The authors would like to thank the Deanship of Scientific Research for funding this work through a Grant no. 4010/430. In addition, thanks are due to Professor Yehia AlHamed, Chairman of Chemical and Materials Department for his support with some equipments from his laboratory. They would like also to thank Engineer. Alawy from the Production Engineering Department for his help in doing SEM images of their Samples.

\section{References}

[1] A. Formhals, "Process and apparatus for preparing artificial threads," US Patent 1975504, 1934.

[2] A. Formhals, "Method and apparatus for spinning," US Patent 2160962, 1939.

[3] A. Formhals, "Artificial thread and method of producing same," US Patent 2187306, 1940.

[4] G. L. Taylor, "Electrically driven jets," Proceedings of the Royal Society of London A, vol. 313, p. 453, 1969.

[5] Z. M. Huang, Y. Z. Zhang, M. Kotaki, and S. Ramakrishna, "A review on polymer nanofibers by electrospinning and their applications in nanocomposites," Composites Science and Technology, vol. 63, no. 15, pp. 2223-2253, 2003.

[6] J. S. Kim and D. H. Reneker, "Polybenzimidazole nanofiber produced by electrospinning," Polymer Engineering and Science, vol. 39, no. 5, pp. 849-854, 1999.

[7] X. Fang and D. H. Reneker, "DNA fibers by electrospinning," Journal of Macromolecular Science Part B, vol. 36, no. 2, pp. 169-173, 1997.

[8] J. Doshi and D. H. Reneker, "Electrospinning process and applications of electrospun fibers," Journal of Electrostatics, vol. 35, no. 2-3, pp. 151-160, 1995.

[9] F. Abdel-Hady, "Upward spinning," US Patent 60701099, 2005.

[10] F. Abdel-Hady and M. Hamed, in Proceedings of the Egyptian Engineers Association Conference, Al Riad, Saudi Arabia, 2009.

[11] D. H. Reneker, A. L. Yarin, H. Fong, and S. Koombhongse, "Bending instability of electrically charged liquid jets of polymer solutions in electrospinning," Journal of Applied Physics, vol. 87, no. 9, pp. 4531-4547, 2000.
[12] M. M. Hohman, M. Shin, G. Rutledge, and M. P. Brenner, "Electrospinning and electrically forced jets. I. Stability theory," Physics of Fluids, vol. 13, no. 8, pp. 2201-2220, 2001.

[13] J. H. He, Y. Q. Wan, and J. Y. Yu, "Allometric scaling and instability in electrospinning," International Journal of Nonlinear Sciences and Numerical Simulation, vol. 5, no. 3, pp. 243-252, 2004.

[14] J. H. Yu, S. V. Fridrikh, and G. C. Rutledge, "The role of elasticity in the formation of electrospun fibers," Polymer, vol. 47, no. 13, pp. 4789-4797, 2006.

[15] G. Taylor, "Disintegration of water drops in an electric field," Proceedings of the Royal Society A, vol. 280, p. 383, 1964.

[16] K. Garg and G. L. Bowlin, "Electrospinning jets and nanofibrous structures," Biomicrofluidics, vol. 5, no. 1, Article ID 013403, 2011.

[17] D. H. Reneker and I. Chun, "Nanometre diameter fibres of polymer, produced by electrospinning," Nanotechnology, vol. 7, no. 3, pp. 216-223, 1996.

[18] C. J. Buchko, L. C. Chen, Y. Shen, and D. C. Martin, "Processing and microstructural characterization of porous biocompatible protein polymer thin films," Polymer, vol. 40, no. 26, pp. 7397-7407, 1999.

[19] Y. M. Shin, M. M. Hohman, M. P. Brenner, and G. C. Rutledge, "Electrospinning: a whipping fluid jet generates submicron polymer fibers," Applied Physics Letters, vol. 78, no. 8, pp. 1149-1151, 2001.

[20] X. Y. Yuan, Y. Y. Zhang, C. Dong, and J. Sheng, "Morphology of ultrafine polysulfone fibers prepared by electrospinning," Polymer International, vol. 53, no. 11, pp. 1704-1710, 2004.

[21] S. Y. Gu and J. Ren, "Process optimization and empirical modeling for electrospun poly(D,L-lactide) fibers using response surface methodology," Macromolecular Materials and Engineering, vol. 290, no. 11, pp. 1097-1105, 2005.

[22] S. Kidoaki, I. K. Kwon, and T. Matsuda, "Structural features and mechanical properties of in situ-bonded meshes of segmented polyurethane electrospun from mixed solvents," Journal of Biomedical Materials Research Part B, vol. 76, no. 1, pp. 219-229, 2006.

[23] S. C. Baker, N. Atkin, P. A. Gunning et al., "Characterisation of electrospun polystyrene scaffolds for three-dimensional in vitro biological studies," Biomaterials, vol. 27, no. 16, pp. 3136-3146, 2006.

[24] L. Wannatong, A. Sirivat, and P. Supaphol, "Effects of solvents on electrospun polymeric fibers: preliminary study on polystyrene," Polymer International, vol. 53, no. 11, pp. 18511859, 2004.

[25] M. Chowdhury and G. Stylios, "Effect of experimental parameters on the morphology of electrospun Nylon 6 fibres," International Journal of Basic and Applied Sciences, vol. 10, no. 6, p. 116, 2006.

[26] J. M. Deitzel, J. Kleinmeyer, D. Harris, and N. C. B. Tan, "The effect of processing variables on the morphology of electrospun nanofibers and textiles," Polymer, vol. 42, no. 1, pp. 261-272, 2001.

[27] C. Mit-Uppatham, M. Nithitanakul, and P. Supaphol, "Ultrafine electrospun polyamide-6 fibers: effect of solution conditions on morphology and average fiber diameter," Macromolecular Chemistry and Physics, vol. 205, no. 17, pp. 23272338, 2004. 

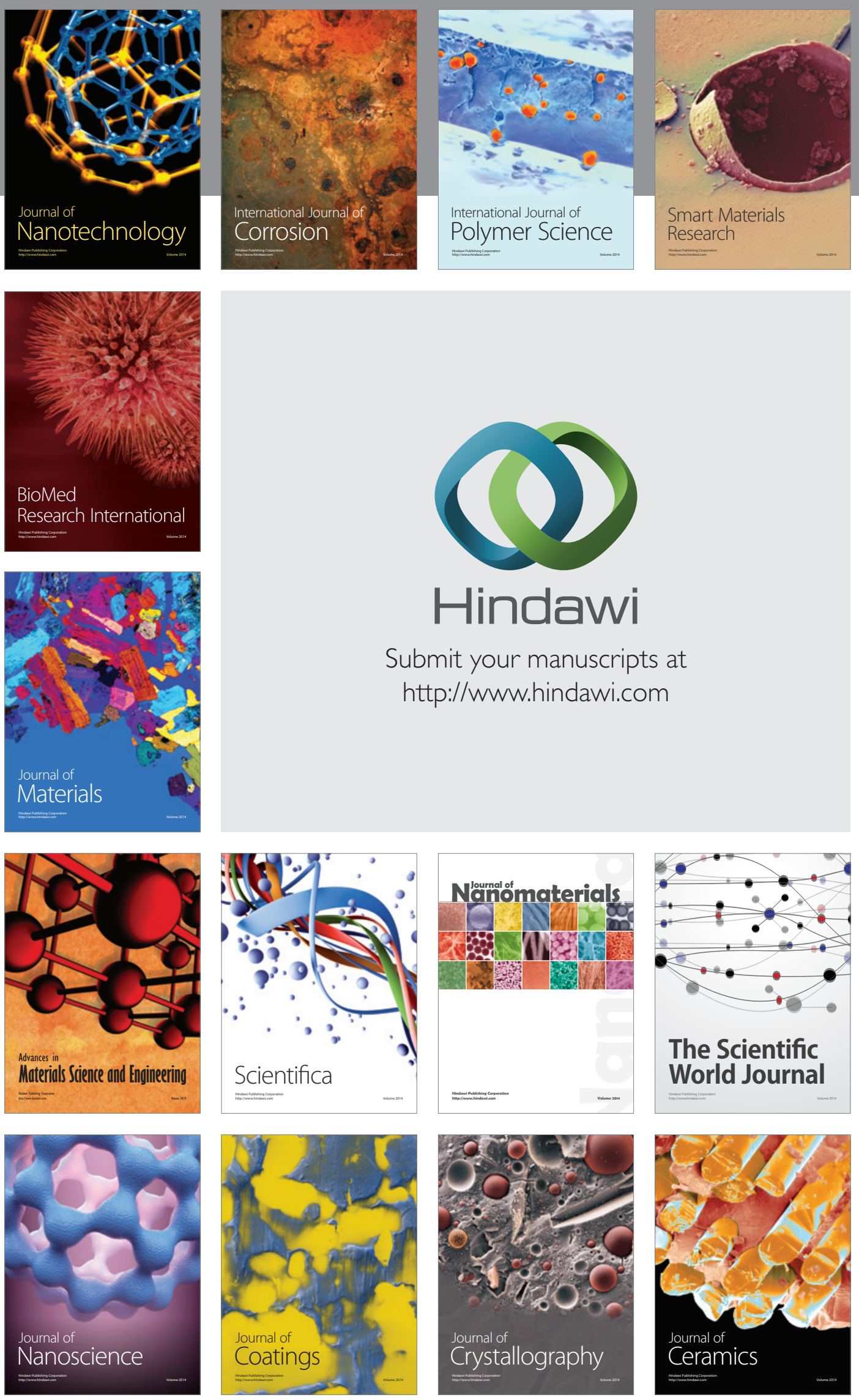

The Scientific World Journal

Submit your manuscripts at

http://www.hindawi.com

\section{World Journal}

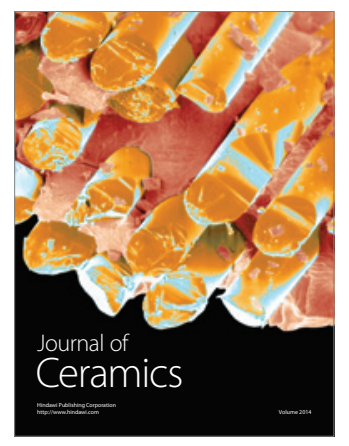

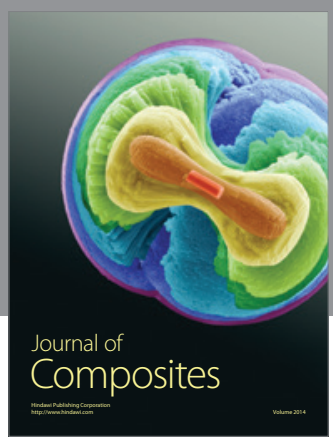
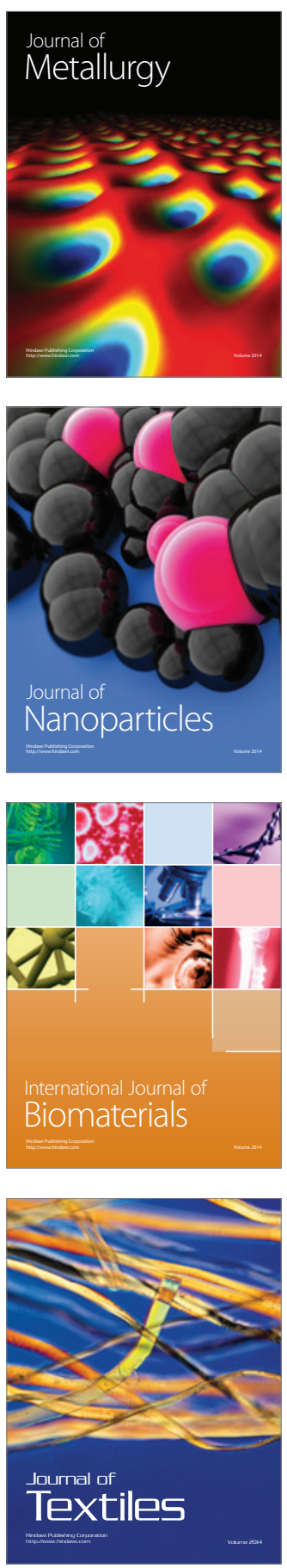